\title{
Profundidades de semeadura para emergência de plântulas de juazeiro
}

\author{
Sowing depths for seedlings emergency of juazeiro
}

\author{
Edna Ursulino Alves ${ }^{I^{*}}$ Riselane de Lucena Alcântara Bruno $^{\mathrm{I}}$ Anarlete Ursulino Alves ${ }^{\mathrm{II}}$ \\ Adriana Ursulino Alves ${ }^{\mathrm{III}}$ Edson de Almeida Cardoso ${ }^{\mathrm{IV}}$ Carina Seixas Maia Dornelas ${ }^{\mathrm{II}}$ \\ Evio Alves Galindo ${ }^{\text {IV }}$ Joel Martins Braga Júnior ${ }^{I V}$
}

\begin{abstract}
Juazeiro (Zizyphus joazeiro Mart.) é uma árvore brasileira típica dos sertões nordestinos. Endêmica da Caatinga, ela ocorre nos diversos Estados do Nordeste do Brasil e apresenta grande potencial econômico e é importante para a região semiárida. Assim, este estudo teve como objetivo determinar a melhor profundidade de semeadura para a emergência de plântulas de Zizyphus joazeiro. O experimento foi realizado em casa-devegetação, tendo como substrato areia lavada e esterilizada contida em bandejas de plástico, com 4 repetições de 25 unidades de dispersão cada uma, nas seguintes profundidades (um, dois, três, quatro e cinco centímetros). A semeadura de juazeiro em ambiente protegido deve ser feita na profundidade entre 1,0 e $1,6 \mathrm{~cm}$, resultando em elevado aproveitamento das unidades de dispersão. A profundidade de $1 \mathrm{~cm}$ resultou em menor tempo para a germinação total.
\end{abstract}

Palavras-chave: Zizyphus joazeiro Mart, espécie florestal, vigor, frutífera nativa.

\section{ABSTRACT}

Zizyphus joazeiro Mart. is a typical Brazilian tree of the northeastern dry lands, being endemic to the Caatinga. It occurs in various states of Northeast Brazil and provides a great economic potential and importance for this semi-arid region. This study had as objective to determine the best sowing depth of Zizyphus joazeiro. In greenhouse sand substratum, with 4 replications of 25 units of dispersion each one, in the following depths (one, too, tree, four and five centimeters). It was ended that the sowing of juazeiro in nursery should be done in the depth of 1.0 to $1.6 \mathrm{~cm}$. The depth of $1 \mathrm{~cm}$ resulted in smaller time for the total germination.

Key words: juazeiro, forest species, vigor, fruitful native.

O juazeiro (Zizyphus joazeiro Mart.), Rhamnaceae é encontrado no Nordeste do país, especialmente nas caatingas e campos abertos do polígono da seca. A madeira é empregada em construções rurais, marcenaria e na confecção de moirões, carvão e lenha. A árvore proporciona sombra e possui qualidades ornamentais, podendo ser empregada com sucesso no paisagismo em geral, especialmente na arborização de ruas e jardins. Os frutos são comestíveis, ricos em vitamina $\mathrm{C}$ e amadurecem entre junho-julho. A emergência das plântulas ocorre entre 70-100 dias e a porcentagem final é geralmente muito baixa, fazendo-se necessário o desenvolvimento de técnicas para superação da resistência mecânica das unidades de dispersão (LORENZI, 2002).

O insucesso na germinação da semente e no estabelecimento inicial da muda no campo está

IDepartamento de Fitotecnia, Centro de Ciência Agrárias (CCA), Universidade Federal da Paraíba (UFPB), CP 02, 58397-000,

Areia, PB, Brasil. E-mail: edanaursulino@cca.ufpb.br. *Autor para correspondência

IIPrograma de Pós-graduação em Agronomia, CCA/UFPB, Areia, PB, Brasil.

IIIPrograma de Pós-graduação em Agronomia, Faculdade de Ciência Agrárias e Veterinária (FCAV), Universidade Estadual Paulista (UNESP), Jaboticabal, SP, Brasil.

${ }^{\mathrm{IV}} \mathrm{CCA} / \mathrm{UFPB}$, Areia, PB, Brasil. 
relacionado, principalmente, a alguns fatores como o contato da semente com o solo, deslocamento do ponto de semeadura, semeadura muito profunda, excesso ou escassez de umidade e perdas de sementes e plântulas para insetos e pássaros (DOUGHERTY, 1990). Quanto à profundidade de semeadura, a ideal é aquela que garanta germinação rápida e homogênea das sementes, rápida emergência das plântulas e produção de mudas vigorosas (SCHMIDT, 1974). Nesse sentido, CHAPMAN \& ALLAN (1989) relataram que a profundidade recomendada para semeadura é de 2,5 a 3,0 vezes a maior dimensão da semente, podendo aprofundar-se mais em locais com solos soltos do que naqueles pesados e argilosos. Já HARTMANN \& KESTER (1983) sugeriram que, em termos práticos, sementes pequenas devem ser espalhadas na superfície do substrato; sementes médias cobertas por uma camada de espessura aproximada de seu diâmetro e sementes grandes a uma profundidade de duas a três vezes o seu diâmetro.

Para sementes de baru (Dipteryx alata Vog.) as maiores porcentagens de germinação (98, 96 e $93 \%$, respectivamente) ocorreram quando as sementes foram semeadas nas profundidades de 1, 2 e $3 \mathrm{~cm}$ (FONSECA et al., 1994). De forma semelhante, PEREZ et al. (1999) também obtiveram as maiores porcentagens de plântulas emersas (46 e 42\%) quando as sementes de canafístula (Peltophorum dubium (Spreng.) Taub.) foram semeadas entre 1,0 e 3,0cm, respectivamente.

A profundidade de $1,5 \mathrm{~cm}$ foi considerada por RODRIGUES \& CARVALHO (2001) como ideal para testes de emergência com sementes de angico (Anadenanthera macrocarpa (Benth.) Brenan). Para açaí (Euterpe oleracea Mart.), SILVA et al. (2007) recomendaram semeadura sob o substrato até $3 \mathrm{~cm}$ de profundidade. No entanto, MENDONÇA et al. (2007) constataram que as profundidades de semeadura ( 0 a $3 \mathrm{~cm}$ ) não influenciaram a emergência de plântulas e o vigor de sementes de gravioleria (Annona muricata L.), devido ao fato dessas profundidades não terem constituído obstáculo à emergência e posterior desenvolvimento das plântulas.

O presente trabalho teve como objetivo avaliar profundidades de semeadura na emergência de plântula de juazeiro.

O trabalho foi realizado em casa-devegetação do Centro de Ciências Agrárias da Universidade Federal da Paraíba, em Areia - PB, com frutos de juazeiro colhidos nas árvores no município de Barra de Santa Rosa-PB. Em seguida, os frutos foram levados para o Laboratório de Análise de Sementes, onde foram despolpados manualmente e tiveram as unidades de dispersão submetidas à fermentação por cinco dias para a retirada da mucilagem. Decorrido esse período, as mesmas foram lavadas em água corrente, sobre peneira de arame e postas para secar a sombra por cinco dias.

Após o beneficiamento, as unidades de dispersão foram semeadas em bandejas plásticas perfuradas no fundo em substrato composto de areia lavada e previamente esterilizada em autoclave, onde a profundidade de semeadura variou de um a cinco centímetros. Cada bandeja constou de quatro repetições de 25 sementes e, após a semeadura, as mesmas permaneceram sobre uma bancada de alvenaria, em ambiente protegido e sob as condições normais de temperatura, fotoperíodo e umidade relativa do ar. Os tratamentos constaram da semeadura em diferentes profundidades (1, 2, 3, 4 e 5cm).

Para a avaliação do efeito dos tratamentos analisaram-se: porcentagem de emergência de plântulas: 100 unidades de dispersão por tratamento, divididas em quatro repetições de 25 . As contagens iniciaram-se aos 21 e estenderam-se até os 68 dias após a semeadura; primeira contagem de emergência: correspondente à porcentagem acumulada de plântulas normais, com valores registrados aos 35 dias após a semeadura; índice de velocidade de emergência (IVE): por meio de contagens diárias das plântulas normais de juazeiro, dos 21 aos 68 após a semeadura e o índice calculado conforme a fórmula proposta por MAGUIRE (1962); comprimento e matéria seca de plântulas: no final do teste de emergência, as plântulas normais de cada repetição foram medidas com o auxílio de uma régua graduada em centímetros e, em seguida, foram submetidas à secagem em estufa regulada a $65^{\circ} \mathrm{C}$ até atingirem massa constante.

O delineamento experimental utilizado foi o inteiramente ao acaso, constando de cinco tratamentos em quatro repetições de 25 sementes. Os dados foram submetidos à análise de variância e de regressão polinomial. Na análise de regressão, os modelos foram escolhidos, sendo selecionado para explicação dos resultados aquele significativo, com maior valor para o coeficiente de regressão $\left(\mathrm{R}^{2}\right)$ pelo teste $t$.

A percentagem de emergência cresceu à medida que se aumentou a profundidade de semeadura, atingindo o máximo de $88 \%$ em 1,6cm. A partir dessa profundidade, verificou-se uma redução acentuada na porcentagem de emergência das plântulas, chegando a valores próximos a $40 \%$ na profundidade de $5 \mathrm{~cm}$ (Figura 1A). A redução da porcentagem de emergência, nas maiores profundidades, pode ser justificada pela maior dificuldade das plântulas superarem o obstáculo que se constitui o substrato. SILVA et al. (2007) também observaram redução na porcentagem de emergência de plântulas de açaí (Euterpe oleracea Mart.), na 


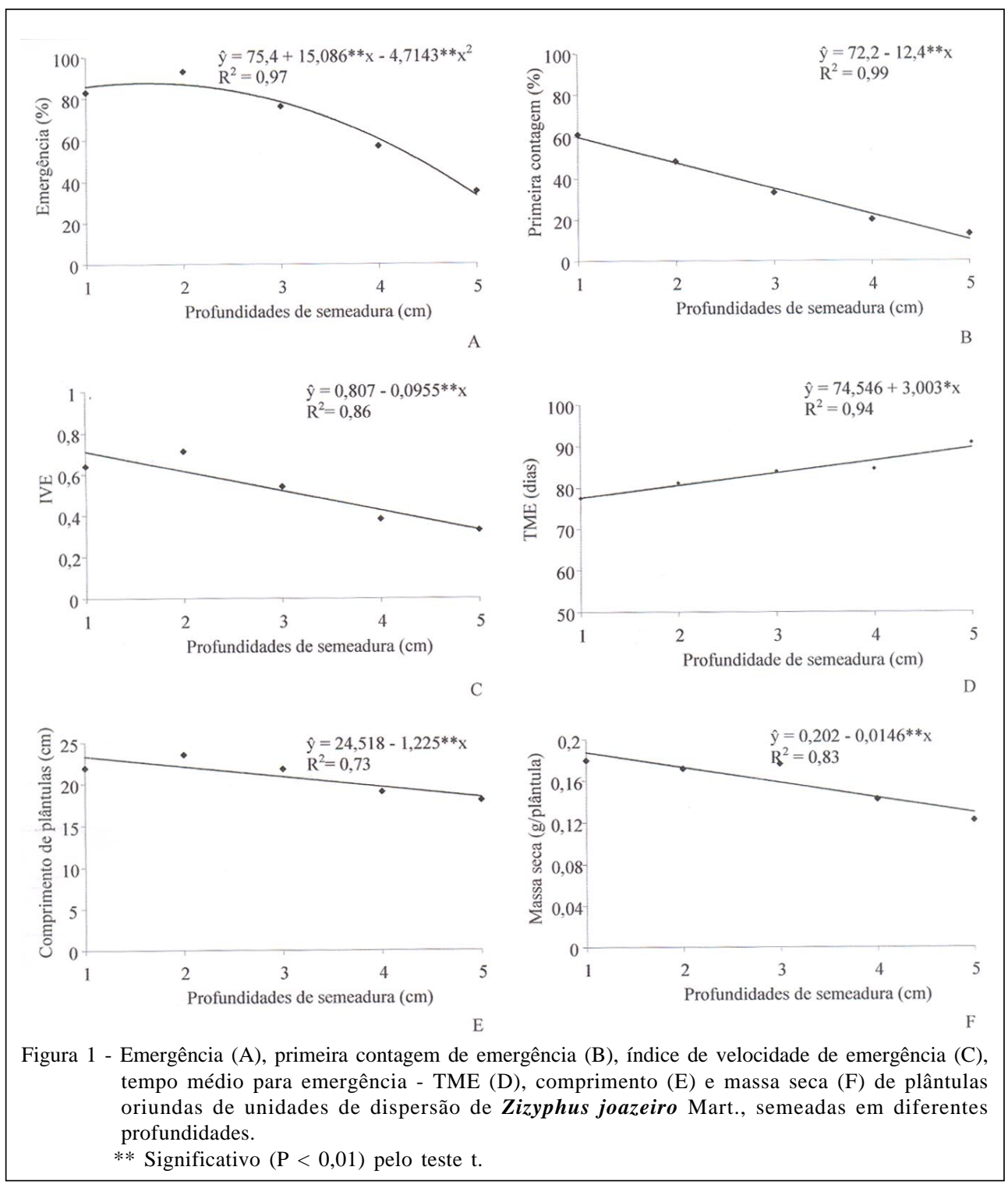

medida em que aumentaram a profundidade de semeadura, sendo os melhores resultados constatados a um centímetro.

Para a primeira contagem de emergência (Figura 1B), verificou-se uma redução de $12,4 \%$ na porcentagem de emergência, a cada centímetro de aumento na profundidade de semeadura. De forma semelhante, PEREZ et al. (1999) relataram que houve redução na porcentagem e velocidade de emergência de plântulas de Peltophorum dubium (Spreng.) Taub. à medida que se aumentou a profundidade de semeadura, sendo os menores valores obtidos a partir de três centímetros.

De forma semelhante ao ocorrido para a primeira contagem, também se verificou uma redução de 0,09 no índice de velocidade de emergência, a cada centímetro de aumento na profundidade de semeadura (Figura 1C). Com o aumento na profundidade de semeadura, as plântulas consumiram mais energia durante o processo germinativo, o que proporcionou uma emergência mais lenta. Em gravioleira - Annona muricata L. (MENDONÇA et al., 2007) as profundidades de 1,0 a 3,0cm não afetaram o índice de velocidade de emergência das plântulas.

Quanto ao tempo médio para emergência, verificou-se que o aumento na profundidade de semeadura resultou em emergência mais lenta e desuniforme, sendo que o maior tempo médio ocorreu nas unidades de dispersão semeadas na maior profundidade (Figura 1D). Esses resultados devem-se, 
provavelmente, a um maior consumo das reservas das unidades de dispersão para conversão em energia para que as plântulas conseguissem romper o impedimento físico constituído pelo substrato. Tais resultados estão de acordo BRUM et al. (1999), quando relataram que, nas maiores profundidades de semeadura, devido ao maior tempo necessário para superar a camada de cobertura, as sementes Pinus taeda L. devem ter sofrido um desgaste fisiológico maior até a emergência, podendo, nestes casos, dar origem a plântulas mais debilitadas e conseqüentemente com menor capacidade de sobrevivência, no período subsequente.

À semelhança da primeira contagem e do índice de velocidade de emergência, também se verificou uma redução de $1,22 \mathrm{~cm}$ no comprimento das plântulas, a cada centímetro de aumento na profundidade de semeadura (Figura 1E). Provavelmente houve um grande gasto de energia durante a fase de emergência, o que prejudicou o desenvolvimento normal das plântulas oriundas de sementes submetidas às maiores profundidades. BRUM et al. (1999) registraram que sementes de pinheiro (Pinus taeda L.), nas maiores profundidades (três e cinco centímetros), devem ter sofrido um desgaste fisiológico maior até a emergência, devido ao maior tempo gasto para superar a camada de cobertura, podendo, nestes casos, dar origem a plântulas mais debilitadas e conseqüentemente com menor capacidade de sobrevivência.

Conforme dados da figura $1 \mathrm{~F}$, à semelhança de todas as características que representam o vigor, constatou-se redução de $0,015 \mathrm{~g}$ na matéria seca das plântulas a cada centímetro de aumento na profundidade de semeadura. De forma diferente, PEREZ et al. (1999) observaram que as profundidades de semeadura (um a cinco centímetros) não influenciaram o conteúdo de matéria seca de plântulas de canafístula (Peltophorum dubium (Spreng.) Taub.).

O aumento da barreira física proporcionado pelas camadas mais profundas, a partir de $1 \mathrm{~cm}$, foi, provavelmente, determinante para o aumento do tempo médio de emergência e, conseqüentemente, para a diminuição de todas as características analisadas, de forma que as profundidades de semeadura entre $1 \mathrm{e}$ $1,6 \mathrm{~cm}$ são ideais para testes de emergência e vigor de plântulas de juazeiro em casa-de-vegetação.

\section{REFERÊNCIAS}

BRUM, E.S. et al. Emergência e sobrevivência de Pinus taeda L. em semeadura direta a diferentes profundidades. Revista Brasileira de Agrociência, Pelotas, v.5, n.3, p.190-194, 1999.

CHAPMAN, G.W., ALLAN, T.G. Técnicas de estabelecimento de plantaciones forestales. Roma: FAO, Organizacion Das Naciones Unidas Para La Agricultura y La Alimentación, 1989. 206p.

DOUGHERTY, P.M. A field investigation of the factors which control germination and establishment of loblolly pine seeds. Georgia: FRDA - Forestry Commission, 1990. 5p. (Forestry Commission, 7).

FONSECA, C.E.L. et al. Influência da profundidade de semeadura e da luminosidade na germinação de sementes de baru (Dipteryx alata Vog.). Pesquisa Agropecuária Brasileira, Brasília, v.29, n.4, p.653-659, 1994

HARTMANN, H.T.; KESTER, D.E. Plant propagation: principles and practices. New York: Englewood Clipps, PrenticeHall, 1983. 727p.

LORENZI, H. Árvores brasileiras: manual de identificação e cultivo de plantas arbóreas nativas do Brasil. 4.ed. Nova Odessa: Instituto Plantarum, 2002. 384p.

MAGUIRE, J.D. Speed of germination - aid in selection and evaluation for seedling emergence and vigor. Crop Science, Madison, v.2, n.2, p.176-177, 1962.

MENDONÇA, W. et al. Superação de dormência e profundidade de semeadura de sementes de gravioleira. Caatinga, Mossoró, v.20, n.2, p.73-78, 2007.

PEREZ, S.C.J.G. A. et al. Influência do armazenamento, substrato, envelhecimento precoce e profundidade de semeadura na germinação de canafístula. Bragantia, Campinas, v.58, n.1, p.57-68, 1999

RODRIGUES, V.E.G.; CARVALHO, D.A. Levantamento etnobotânico de plantas medicinais no domínio do cerrado na região do alto Rio Grande - Minas Gerais. Revista Ciência e Agrotecnologia, Lavras, v.25, n.1, p.102-123, 2001.

SCHMIDT, P.B. Sobre a profundidade ideal de semeadura do mogno (aguano) Swietenia macrophylla King. Brasil Florestal, Brasília, v.5, n.17, p.42-47, 1974.

SILVA, B.M.S. et al. Influência da posição e da profundidade de semeadura na emergência de plântulas de açaí (Euterpe oleracea Mart. - Arecaceae). Revista Brasileira de Fruticultura, Jaboticabal, v.29, n.1, p.187-190, 2007. 